\title{
Case report on placenta accreta presenting obstetric emergency
}

\author{
Vishal Sharma*, Jashandeep Kaur
}

Department of Obstetrics and Gynecology, MMIMSR, Mullana, Ambala, Haryana, India

Received: 08 March 2017

Accepted: 07 April 2017

*Correspondence:

Dr. Vishal Sharma,

E-mail: priitisharma.micro@gmail.com

Copyright: (c) the author(s), publisher and licensee Medip Academy. This is an open-access article distributed under the terms of the Creative Commons Attribution Non-Commercial License, which permits unrestricted non-commercial use, distribution, and reproduction in any medium, provided the original work is properly cited.

\begin{abstract}
Placenta accreta is a potentially life-threatening obstetric condition that requires a multidisciplinary approach to management. As the incidence of Caesarean have increased, Placenta accreta also has increased and considered as an important cause of maternal and fetal/neonatal morbidity and mortality. Although multiple caesarean deliveries are at the largest risk factor for the placenta accreta, increasing maternal age and parity, as well as other uterine surgeries are also important. In Patient at risk for accreta, obstetrical ultrasonography performed by an experienced provider should be obtained. A multidisciplinary team in a centre with expertise in managing placenta accreta should care for case of suspected accreta.
\end{abstract}

Keywords: Caesarean, Hysterectomy, Obstetric hemorrhage, Placenta accreta

\section{INTRODUCTION}

Placenta accrete is a potential grievous obstetric condition that call for a multidisciplinary avenue for timely management. Placenta accreta refers to placenta that abnormally attaches directly onto or into the myometrium. ${ }^{1}$ Three levels of abnormal placental attachments are outlined according to the profundity of invasion, namely Placenta accreta - the utrine deciduas is absent and the chronic villi attaches to the myometrium directly. Placenta increta-the chronic villi invades into the myometrium. Placenta percreta-the chronic villi encroach through the myometrium and may permeate to close by organs. ${ }^{2,3}$

It is also colligated with Placenta pervia. Clinically placenta accreta becomes baffling during delivery when the placenta does not entirely asunder from the uterus and is ensued by massive obstetric hemorrhage, leading to disseminated intravascular coagulopathy; the need of hysterectomy; surgical injury to the ureters, bladders, bowel, or neuromuscular structures; adult respiratory distress syndrome; acute transfusion reaction; electrolyte imbalance; and renal failure. The average blood loss at delivery in women with placenta accrete is 3000-5000 ml. ${ }^{4}$ The incidence of placenta accrete is 1 in 2500 according to Shinder, $\mathrm{S}$ et al. ${ }^{2}$ But there is a run-up in the frequency of placenta accreta 3\%,11\%, 40\%, $61 \%$ and $67 \%$ in first, second, third, fourth and fifth caesarean it seem to be parallel to the increasing cesarean delivery rate. The ultrasound and magnetic resonance image (MRI) may or may not indicate clearly an invasive placenta, however final diagnosis is made intraoperatively and supported by histopathological examination.

\section{CASE REPORT}

A 25 years old married Indian female; G3P2L2A0; with previous two sane vaginal deliveries presented with shock to the emergency department. Her gestational age was 30 wks 6days by LMP. She had a history of loss of fetal movements since 4 days and bleeding per vaginum since 2 days. The antenatal period was uneventful until her presentation at 30 weeks 6 days of gestation with bleeding per vaginum \& loss of fetal movements. She was very wan and hemodynamically unstable, cold and clammy extremities with blood pressure 80/50 and pulse $116 / \mathrm{min}$ and low volume. On abdominal examination, the uterine contour was intact, uterus 30 wks size, relaxed, 
breech presentation. The fetal heart rate could not be localized. The abdomen was mildly distended with muscle guarding present. The decision for caesarean section was made with the provisional diagnosis of placental abruption. She was taken to the operating theatre within 30 minutes from the time of admission. General anesthesia was given. Lower segment caesarean section was done revealing clear amniotic fluid. Placenta was lying posteriorly reaching upto os. An IUD male baby was delivered as breech.

A part of placenta extracted out. But some part of placenta $(3 \times 3 \mathrm{~cm})$ was centrally adherent to posterior wall of lower uterine segment and diagnosis of placenta accreta was made. Uterus was flabby irrespective of uterotonics. Urgent decision of hysterectomy was taken i/v/o placenta accreta. Total hysterectomy was done. 2 units of whole blood were transfused intra-operatively. Post operatively, she was transferred to the intensive care unit and received a blood transfusion of 4 units, which had a significant impact on her post-operative recovery. She recovered well and was discharged on 8th postoperative day. The specimen was sent for histopathological examination which reveals placental villi extending deeply into the myometrium of the lower uterine segment, suggestive of placenta accreta in the lower uterine segment.

\section{DISCUSSION}

The relative incidence of all sorts of placental adhesion (placenta accreta, increta and percreta) has been up rising for the past two decades, due to increasing caesarean section rates. Other predisposing conditions are instrumentation of the endometrium, placenta praevia, uterine malformations, septic endometritis, previous manual removal of placenta and multiparity. A risk of placenta accreta exists in 2 to $5 \%$ with any case of placenta previa. In these cases, resuscitation procedures (when appropriate) and an urgent hysterectomy appears to be the treatment of choice. Antecedently, a conservative treatment, aiming at uterine rescue, was followed to a greater extent, based upon manual removal of as much placental tissue as possible. Fox et al. reported that $25 \%$ of the women died during this treatment. ${ }^{4}$ Under these circumstances, the more conservative treatment can be achieved only in cases of a partial placenta accreta/ increta, when bleeding is minimal. Alternative interventions include ligature of uterine artery or internal iliac artery, or angiographic embolization. ${ }^{5}$ There are a number of risk factors leading to hemoperitoneum during pregnancy.

Previous gynecological procedures, pregnancies, infections and curettage, trophoblastic disease, and endometrial or cervical malignancies favor such an occurrence. ${ }^{6}$ Spontaneous uterine rupture may also follow adenomyosis, instrumental termination, manipulations during labor, misoprostol-induced labor, or cocaine misuse. In some cases, no cause can be identified, and these are considered idiopathic. ${ }^{7-9}$ Magnetic resonance imaging and Doppler sonography can be used for the prenatal diagnosis of placenta increta. ${ }^{10}$ However, the diagnostic value of sonography in prenatal diagnosis of an asymptomatic placenta increta is uncertain. A positive predictive value of $78 \%$ and a negative predictive value of $94 \%$ has been reported by Finberg et al, but some of other authors suggested that sonography might detect only around $33 \%$ of cases of placenta accreta/increta. ${ }^{11,12}$ Regarding treatment, hysterectomy is probably the best option for long-term outcome, as previously reported. ${ }^{13}$ Numbers of attempts have been made to treat placenta increta with various drugs to allow the pregnancy to continue. ${ }^{14}$ Methotrexate, is the drug most widely used, although its safety and the efficacy in this setting are questionable. $^{15,16}$

\section{CONCLUSION}

It is potential life threatening condition for both mother and baby. Inspite of early diagnosis of placenta accreta/increta through MRI, Hysterectomy remains a common procedure. This case highlights need for further research into the prevention of abnormal placental development and to prevent their risk of massive hemorrhage.

\section{ACKNOWLEDGEMENTS}

Author would like to thanks to Sorabh Singh Sambyal, $\mathrm{Ph}$. D Scholar for his contribution for the successful completion of this research article.

Funding: No funding sources

Conflict of interest: None declared

Ethical approval: Not required

\section{REFERENCES}

1. Stocker J, Dehner L. Pediatric Pathology Volume One Lippincott Williams and Wilkin. USA; 2001.

2. Shnider S, Levinson G. Anesthesia for Obstetrics 3rd Edition Williams and Wilkins. USA; 1993.

3. Gielchinsky Y, Rojansky N, Fasouliotis S. Placenta Accreta - Summary of 10 Years: A Survey of 310 Cases Placenta. 2002;23:210-4.

4. Shellhaas CS, Gilbert S, Landon MB, Varner MW, Leveno KJ, Hauth JC, et al. The frequency and complication rates of hysterectomy accompanying cesarean delivery. Eunice Kennedy Shriver National Institutes of Health and Human Development Maternal-Fetal Medicine Units Network. Obstet Gynecol. 2009; 114:224-9.

5. Liu X, Fan G, Jin Z, Yang N, Jiang Y, Gai M, et al. Lower uterine segment pregnancy with placenta increta complicating first trimester induced abortion: diagnosis and conservative management. Chin Med J. 2003;116:695-8.

6. Yang JJ, Xiang Y, Wan XR, Yang XY. Diagnosis and management of uterine arteriovenous fistulas 
with massive vaginal bleeding. Int $\mathrm{J}$ Gynaecol Obstet. 2005;89:114-9.

7. Berghahn L, Christensen D, Droste S. Uterine rupture during second trimester abortion associated with misoprostol. Obstet Gynecol. 2001;98:976-7.

8. Mishra A, Landzberg BR, Parente JT. Uterine rupture in association with alkaloidal cocaine abuse. Am J Obstet Gynecol. 1995;173:243-4.

9. Sallam AH, Preston J. Idiopathic uterine perforation in late pregnancy. J Obstet Gynaecol. 2002;22:31720.

10. Gielchinsky Y, Rojansky N, Fasouliotis SJ, Ezra Y. Placenta accreta-summary of 10 years: a survey of 310 cases. Placenta. 2002;23:210-4.

11. Finberg HJ, Williams JW. Placenta accreta: prospective sonographic diagnosis in patients with placenta previa and prior cesarean section. J Ultrasound Med. 1992;11:333-43.

12. Lam G, Kuller J, McMahon M. Use of magnetic resonance imaging and ultrasound in the antenatal diagnosis of placenta accreta. J Soc Gynecol Investig. 200;9:37-40.

13. Suner S, Jagminas L, Peipert JF, Linakis J. Fatal spontaneous rupture of a gravid uterus: Case report and literature review of uterine rupture. J Emerg Med. 1996;14:181-5.

14. Crespo R, Lapresta M, Madani B. Conservative treatment of placenta increta with methotrexate. Int $\mathbf{J}$ Gynecol Obstet. 2005;91:162-3.

15. Kayem G, Davy C, Goffinet F, Thomas C, Clement D, Cabrol D. Conservative versus extirpative management in cases of placenta accreta. Obstet Gynecol. 2004;104:531-6.

16. Liao CHY, Ding DCH. Failure of conservative treatment for placenta increta. Taiwan J Obstet Gynecol. 2009;48:302-4.

Cite this article as: Sharma V, Kaur J. Case report on placenta accreta presenting obstetric emergency. Int J Reprod Contracept Obstet Gynecol 2017;6:2112-4. 